\title{
Mathematical Modeling of Electrolyte Flow in a Single Flow Channel over Porous Electrode Layered System in Vanadium Flow Battery
}

\author{
Xinyou Ke $e^{\text {a,b,e, }}$, Joseph M. Prahl ${ }^{\mathrm{a}}$, J. Iwan D. Alexander ${ }^{\mathrm{a}, \mathrm{c}}$, and Robert F. Savinell ${ }^{\mathrm{d}, \mathrm{e}}$
}




\begin{abstract}
In this work, a two-dimensional mathematical model is developed to study the flow patterns and volumetric flow penetrations in a single flow channel over porous electrode layered system in vanadium flow battery. The flow distributions at the interface between the flow channel and porous electrode are examined. It is found that the non-linear pressure distributions can distinguish the interface flow distributions under the ideal plug flow and ideal parabolic flow inlet boundary conditions. However, the volumetric flow penetration within the porous electrode beneath the flow channel through the integration of interface flow velocity reveals that this value is identical under both ideal plug flow and ideal parabolic flow inlet boundary conditions. The volumetric flow penetrations under the advection effects of flow channel and landing/rib are estimated. The maximum current density achieved in the flow battery can be predicted based on the $100 \%$ amount of electrolyte flow reactant consumption through the porous electrode beneath flow channel and landing/rib. The corresponding theoretical maximum current densities achieved in vanadium flow battery with one and three layers of SGL 10AA carbon paper electrode have reasonable agreement with experimental results under a proper permeability.
\end{abstract}

Keywords: flow battery with flow field model; interface flow distributions; pressure distributions; volumetric flow penetrations; ideal parabolic and plug flow inlet conditions 


\section{Nomenclature}

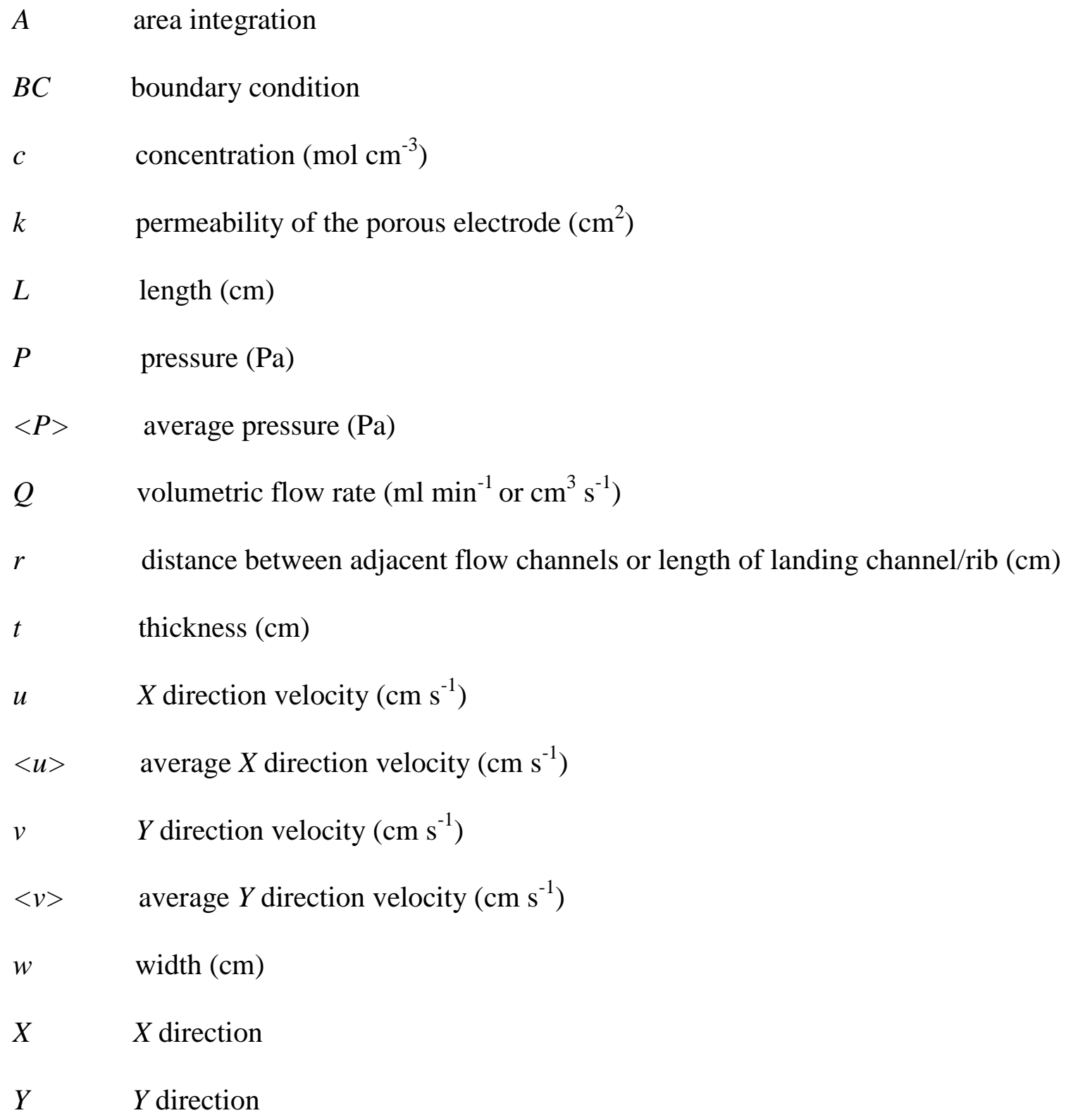




$$
\begin{array}{ll}
\rho & \text { density of electrolyte fluid }\left(\mathrm{g} \mathrm{cm}^{-3}\right) \\
\Sigma & \text { interface }
\end{array}
$$

Subscripts

avg average value

$c f \quad$ between current collector and flow channel

$e \quad$ entrance

$f \quad$ flow domain

fc flow channel

$f p \quad$ between flow channel and porous electrode

in inlet

$i \quad$ number $(1,2,3,4,5$ and 6$)$

lc landing/rib-corner channel

p porous domain

pm between porous electrode and ion selective membrane

Dimensionless number

$P_{f}^{*} \quad P_{f}\left(\rho u_{i n}^{2}\right)^{-1}$

$\left.<P_{p}\right\rangle^{*} \quad\left\langle P_{p}>\left(\rho u_{i n}{ }^{2}\right)^{-1}\right.$

$u_{f}^{*} \quad u_{f} u_{i n}^{-1}$

$<u_{p}>^{*} \quad\left\langle u_{p}>u_{i n}^{-1}\right.$

$v_{f}^{*} \quad v_{f} u_{i n}^{-1}$

$\left\langle v_{p}\right\rangle^{*} \quad\left\langle v_{p}>u_{i n}^{-1}\right.$ 


$$
\begin{array}{ll}
X^{*} & X L^{-1} \\
Y^{*} & Y\left(t_{f}+t_{p}\right)^{-1} \\
\operatorname{Re} & \text { Reynolds number }\left(\rho u_{\text {in }} t_{f} / \mu\right)
\end{array}
$$

\section{Introduction}

Redox flow batteries (RFBs) technologies have been gained unprecedented attention for medium and large-scale energy storage applications [1-3]. In conjunction with electric generation from intermittent renewable energy sources (e.g. wind, tide and solar energy), RFBs systems are demonstrated to be alternative tools within enabling to improve stability of national grid [4]. Until now, several types of RFBs have been developed, typically such as vanadium [5,6], ironchromium [7,8], all iron aqueous/all iron slurry [9], semi-solid lithium [10], etc. Designs of new electrolytes and flow cell architectures attract researchers in the field of flow batteries. The studies on working mechanism of flow batteries are still going on. In this effort, we will study the transport mechanism in a typical all vanadium redox flow battery (VRFB) [4,11-13] and one advantage for the VRFB is that species can be reversibly consumed in the electrolyte reservoir [5]. Experiments and mathematical modeling are two approaches to study the fundamental insights. Compared with experimental studies, the capital costs and labor effort can be reduced while crucial understanding of transport phenomena also can be achieved through the computational modeling $[14,15]$. Earlier work on mathematical modeling of redox flow batteries was reported by Newman et al. $[16,17]$ and they proposed a one-dimensional theoretical model to study current distributions and non-uniform kinetic reactions though the porous electrode. Shah et al. [18] developed a two-dimensional vanadium flow battery without flow channel model to study the transport physics including convection, diffusion and migration in the electrode. Subsequently, You et al. [19] studied the parameter effects on the distributions of local reactant 
concentration, over-potential and current density based on the previous reported two-dimensional flow battery without flow field model [18]. A two-dimensional transient vanadium flow battery without flow field model was developed by Knehr et al. [15]. The species crossover at the interface boundary between the electrode and membrane were studied. The worked done by Newman et al. [16,17], Shah et al. [18], You et al. [19] and Knehr et al. [15] were on flow batteries without flow fields through the felts (e.g. carbon and graphite felts). However, Aaron et al. [20] first reported a vanadium flow cell stack configuration with serpentine flow field over carbon paper electrode. The electrochemical performance (e.g. limiting current density and peak power density) was greatly improved. The thickness of carbon paper electrode $(\sim 0.04 \mathrm{~cm})$ [20] used in vanadium flow battery with flow field is much thinner than the graphite felt or carbon felt (typical $\sim 0.3 \mathrm{~cm}$ ) $[18,19]$ used in the one without flow field. Here, the flow channels, such as serpentine and interdigitated flow fields were evolved from proton exchange membrane fuel cell (PEMFC) design [20,21]. Up to date, few theoretical studies on details of RFBs with flow fields have been reported. Ke et al. [22] developed a macroscopic model of RFBs with a single passage of the serpentine flow channel. Both numerical and analytical flow distributions in the flow channel and porous electrode were studied $[23,24]$. The first mathematical model for predicting the maximum current density achieved in the flow battery with flow fields was proposed. This maximum current density model is based on the consumption of total flow ion reactants through the porous electrode in the RFBs with flow field designs. The thinner carbon fiber paper electrodes (typical 10AA SGL and Toray paper) used in the RFBs with flow fields (e.g., serpentine and interdigitated flow channels) can reduce ohmic losses compared with the conventional RFBs without flow fields. The electrochemical performance of flow cell with flow field design can be improved. There are two porous electrode configurations of RFBs: (1) the 
classic RFBs without flow field [14-19] as shown in Fig. 1 (a), the electrolyte flow through a thick electrode and (2) the RFBs with flow field [20-26] as shown in Fig. 1 (b), the electrolyte flows through the flow channel and by-pass into a thinner electrode. The fundamental studies on the flow details in the flow batteries with flow field designs are quite few. The deep mechanism of electrolyte flow reactant penetration into the porous electrode from the flow channel is not well understood. There are two typical experimental approaches to characterize the electrolyte flow dispersion: visualization [27] and residence time distribution (RTD) [28] techniques. The visualization technique can capture the transport process (e.g. streamline) of electrolyte flow and RTD can calculate the time that particles go through the reactors based on the probability function. Although both visualization and RTD approaches are always prior to multiphysics modeling on characterization of flow dispersion, it seems that they have less capabilities of capturing how much amount of electrolyte flow penetration through the porous electrode. In this study, the amount of electrolyte flow penetration from the flow channel into the porous electrode is concerned. The flow penetration and possible maximum current density achieved based on $100 \%$ utilization of electrolyte through the porous electrode is correlated. Thus, the multiphysics modeling approach is preferred to visualization and RTD techniques in this study on electrolyte flow penetration.

The motivation of this work on vanadium flow battery with flow field design over carbon paper electrodes compared with classic one without flow field design through the carbon felts is based on two possible merits: (1) the forced convection through the flow fields can enhance the mass transport through the electrode layer and (2) thinner carbon paper electrode (hundred microns) has lower ohmic loss in contrast to the thicker carbon felts (several millimeters). In this article, we study the flow patterns in the flow channel and porous electrode to explain the role of 
the convection consequently mass transfer in the flow batteries with flow field design as shown in Fig. 1 (b). The flow penetration or volumetric flow rate within the porous electrode is studied under both ideal plug flow inlet and ideal parabolic flow inlet boundary conditions. The maximum current density achieved in the flow cell can be estimated by a function of calculated volumetric flow rate within the porous electrode, number of electron transferred, Faraday constant, ion concentration and contact area between the flow channel and porous electrode. This mathematical model should contribute a certain guidance on performance optimization of flow batteries with flow field designs. 


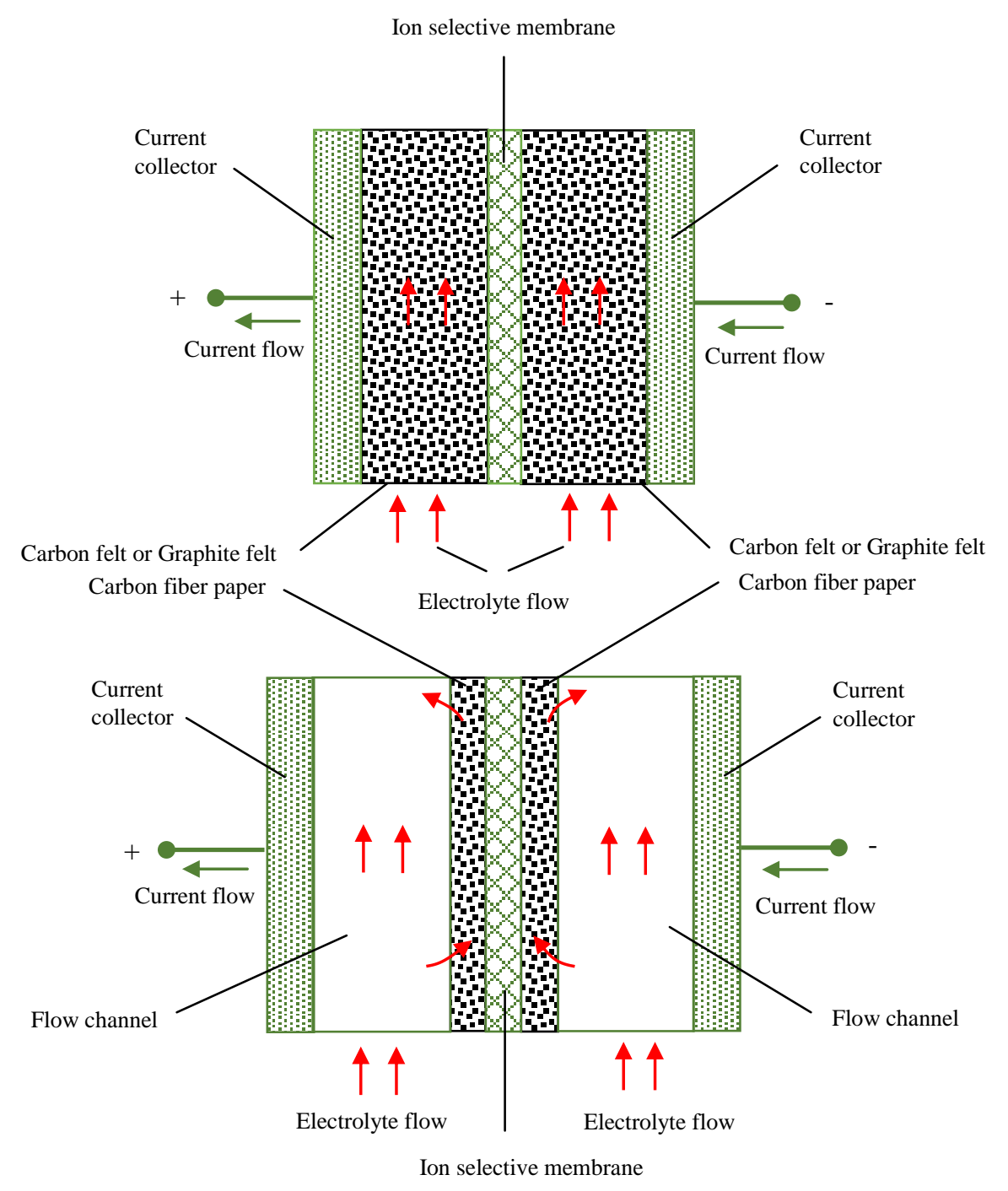

Fig. 1. Two-dimensional configurations of RFBs without and with flow fields: (a) classic flow cell without flow field (not drawn to scale) and (b) flow cell with flow field (not drawn to scale)

\section{Two-dimensional Flow Cell Model}

In this analysis, a simplified two-dimensional model of RFBs with flow field (see Fig. 1 (b)) is shown in Fig. 2 (a) (not drawn to scale) or Fig. 2 (b) (not drawn to scale, see (b. 1)). The actual three-dimensional model of serpentine flow field over the porous electrode as shown in Fig. 2 (b) (not drawn to scale, see (b. 2)) is simplified assumed as several periodic components of main 
straight flow channels (see (b. 1)), corner flow channels (see (b. 2)) and landings/ribs (see (b. 3)).

The volumetric flow penetrations within the porous electrode under the advection effects from

both flow channels and landings/ribs are considered. In this paper, the volumetric flow

penetration under the landing/rib advection is estimated through the calculated volumetric flow

penetration under the flow channel advection. In the flow channel, the corresponding non-

dimensional flow motions along the $X$ and $Y$ directions are governed by Navier-Stokes equation

as shown in Eqs. (1) and (2). The flow physics in the porous electrode are described by

Brinkman-Darcy model [22] with non-dimensional forms as shown in Eqs. (3) and (4) along the

$X$ and $Y$ directions, respectively. The non-dimensional terms are defined in the Nomenclature

section. The dimensionless equations that describe the flow physics in the flow channel and

porous electrode are given

$R e \frac{\left(t_{f}+t_{p}\right)^{2}}{t_{f} \cdot L} u_{f}^{*} \frac{\partial u_{f}^{*}}{\partial X^{*}}+R e \frac{\left(t_{f}+t_{p}\right)}{t_{f}} v_{f}^{*} \frac{\partial u_{f}^{*}}{\partial Y^{*}}=-R e \frac{\left(t_{f}+t_{p}\right)^{2}}{t_{f} \cdot L} \frac{\partial P_{f}^{*}}{\partial X^{*}}+\frac{\left(t_{f}+t_{p}\right)^{2}}{L^{2}} \frac{\partial^{2} u_{f}^{*}}{\partial X^{* 2}}+\frac{\partial^{2} u_{f}^{*}}{\partial Y^{* 2}}$ 
Where, the non-dimensional parameters are defined as: $X^{*}\left(X L^{-1}\right), Y^{*}\left(Y\left(t_{f}+t_{p}\right)^{-1}\right), u_{f}^{*}\left(u_{f} u_{i n}^{-1}\right), v_{f}^{*}$ $\left(v_{f} u_{\text {in }}{ }^{-1}\right)^{1}, P_{f}^{*}\left(P_{f}\left(\rho u_{\text {in }}{ }^{2}\right)^{-1}\right),\left\langle u_{p}>^{*}\left(\left\langle u_{p}>u_{i n}{ }^{-1}\right),\left\langle v_{p}>^{*}\left(\left\langle v_{p}>u_{\text {in }}{ }^{-1}\right),\left\langle P_{p}\right\rangle^{*}\left(\left\langle P_{p}>\left(\rho u_{\text {in }}{ }^{2}\right)^{-1}\right)\right.\right.\right.\right.\right.$ and Re $\left(\left(\rho u_{i n} t_{f} / \mu\right)\right) . t_{f}$ is the length of flow channel, $t_{p}$ is the thickness of flow channel, $L$ is the length of flow channel, $k$ is the permeability of porous electrode and $\varepsilon$ is the porosity of porous electrode.

\section{Simulation Methods and Parameters}

The mathematical model is solved in the multi-physics CFD package COMSOL 3.5 a software together with self-written MATLAB programing codes. The non-linear PARDISO solver is adopted. The type of mesh employed is advancing front triangular unstructured grid. The importance of the mesh density around the interface between the flow channel and porous electrode leads to a refinement of the grids. An example of refined mesh for the part of geometry with one layer of carbon electrode is shown in Fig. 2 (c). The grids independent analysis was made to guarantee the mesh quality. The maximum number of refined grids is 416,840 . The relative tolerance is $10^{-6}$. All the results presented here are independent with mesh number. Twodimensional physical parameters for dimensions, properties and initial operation conditions are given in Table 1 [20,22-24]. The thickness, width and length for a single passage of the serpentine flow channel are measured corresponding to be $0.1 \mathrm{~cm}, 0.1 \mathrm{~cm}$ and $2 \mathrm{~cm}$, respectively. The thickness for a single layer of 10 AA SGL carbon fiber paper electrode is $\sim 0.041 \mathrm{~cm}$. The entrance volumetric flow rate $Q_{i n}=20 \mathrm{~cm}^{3} \min ^{-1}$ gives $u_{i n}=33.3 \mathrm{~cm} \mathrm{~s}^{-1}$ and it is based on the cross section dimension of the flow channel. Compared with classic electrochemical engineering reactors [29-34], there is no turbulence promoter with separation "S" term involved in our VRFB with flow fields. The width (B) of electrode simulated in one segment of flow channel over electrode layer is $0.1 \mathrm{~cm}$. The Reynolds number of electrolyte flow is 91.5 based on the entrance volumetric flow rate of $20 \mathrm{~cm}^{3} \mathrm{~min}^{-1}$ and properties of electrolyte as shown in Table 1. 
The literature on the permeability of typical carbon fiber electrode is limited. Gostick et al. [35] pointed out that this value could be $1 \times 10^{-11} \mathrm{~m}^{2}$ while the one reported by Weber et al. [1] was $2 \times 10^{-11} \mathrm{~m}^{2}$. Nevertheless, the permeability is estimated to be $2.31 \times 10^{-10} \mathrm{~m}^{2}$ through using Carman-Kozney model $[36,37]$. As matter of fact, the degradations [38,39] of carbon paper electrode or carbon felts (typical electrodes used in practical vanadium flow batteries) are hard to be avoidable during the flow battery cycling. The degradation mechanisms of electrodes used in VRFB on their conductivities and permeability are beyond the scope of this study. The permeability of electrode layer is assumed to be invariable in this work. We also have discussed the effect of permeability on volumetric flow penetration and maximum current density in later sections 4.3 and 4.4. 
(b)

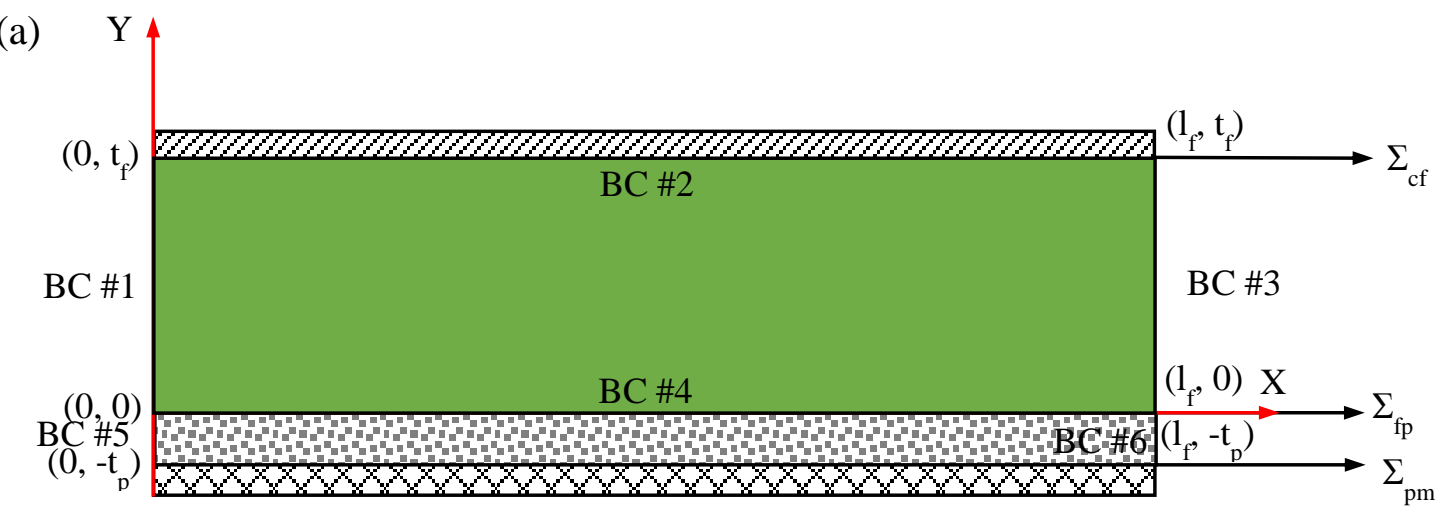

straight flow channel over porous electrode serpentine flow channel

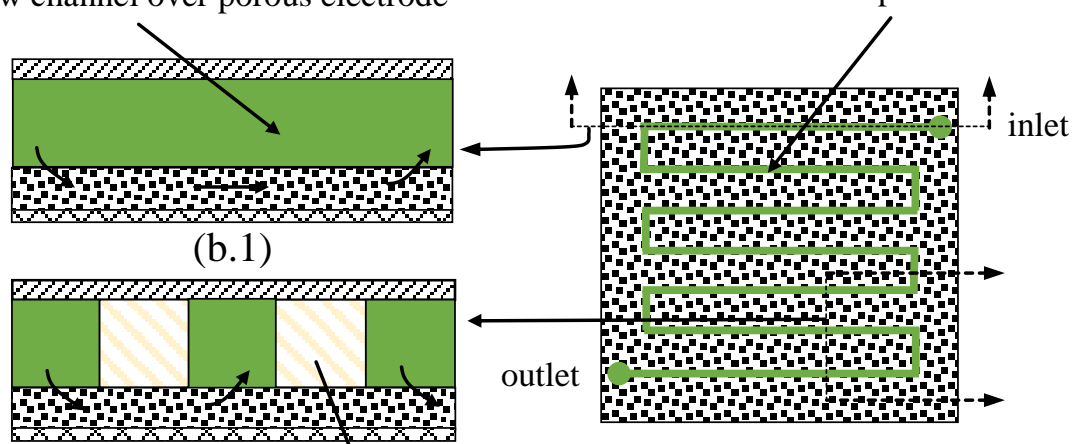

(c)

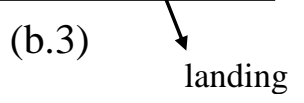

\section{(b.2)}

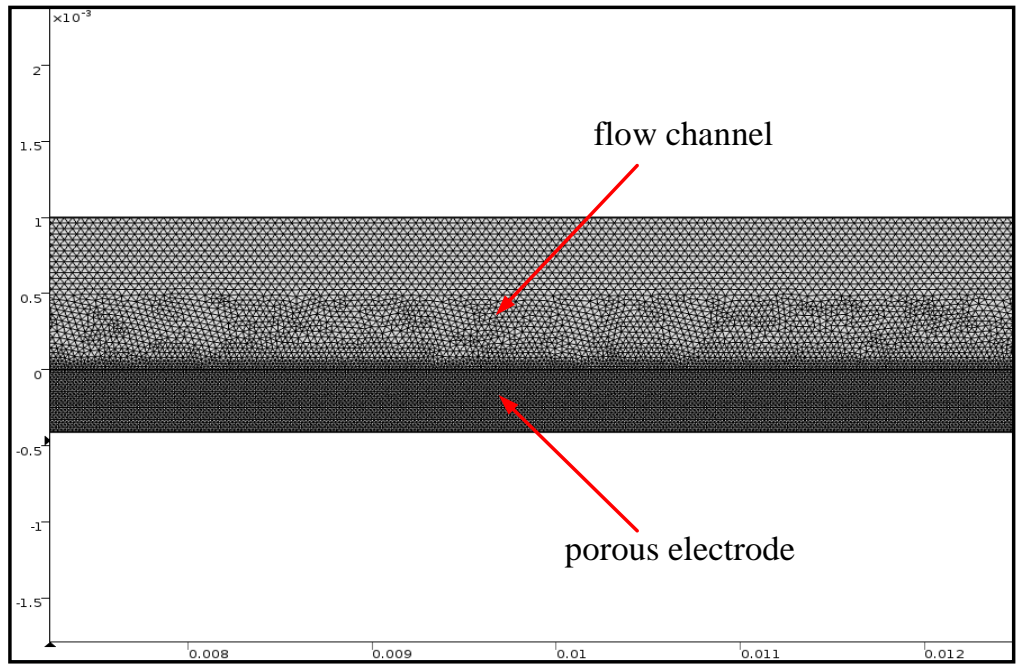


Fig. 2. (a) Two-dimensional model of flowing through the straight flow channel and over the porous electrode in the RFBs with flow field (not drawn to scale); (b) three-dimensional model (not drawn to scale): (b.1) straight flow channel over porous electrode, (b.2) serpentine flow channel over porous electrode and (b.3) landing/rib view of (b.2) and (c) an example of refined mesh for a part of the flow channel and porous electrode domains of (a)

The continuities of flow velocity and normal stress are applied at the interface boundary between the flow channel and porous electrode ( $B C \# 4$, see Fig. 2 (a) ) [40-44]. The flow velocity and pressure type are defined at $B C \# 1$ (see Fig. 2 (a)) and $B C \# 3$ (see Fig. 2 (a)), respectively. $B C \# 2$ (see Fig. 2 (a)), BC \#5 (see Fig. 2 (a)) and BC \#6 (see Fig. 2 (a)) are set as "no slip" boundary conditions. Under the realistic flow cell operation condition in the experiments, plastic tubes are used to connect the tank electrolyte reservoirs and holes in the graphite plates engraved with serpentine flow fields. The layouts of holes and serpentine flow fields are relied on the designs and constructions of flow cell hardware. The possible designs for the incoming electrolyte flow direction in the hole is either perpendicular (see Fig. 3 (a) or (d) and (b) or (e)) or parallel (see Fig. 3 (c) or (f)) to the inlet of serpentine flow field. The only difference between Fig. 3 (a) or (d) and (b) or (e) is the head flow channel. For the case of Fig. 3 (a) or (d), this incoming electrolyte flow directly goes into the flow field after 90 degree turn from the perpendicularly oriented feeder tube. The electrolyte flow does not have any chance to develop and this type of flow is more likely to be uniform [45]. This uniform flow is treated as ideal plug flow inlet condition for the electrolyte flow through the serpentine flow field over electrode layer. Nevertheless, for the case of Fig. 3 (b) or (e), the electrolyte flow has a chance to develop in a head flow channel prior to flow through the serpentine flow field-electrode layer system and this type of flow is more 
likely to be parabolic [45]. This flow mode is considered as ideal parabolic flow inlet condition. The case of Fig. 3 (c) or (f) is not a typical one for the experimental flow cell hardware. Under the parallel flow condition, the incoming electrolyte flow has a chance to develop through the plastic tube without any 90 degree turn from the plastic feeder tube. It is likely that the fully developed regime is approached. This type of flow condition is similar to the one of Fig. 3 (b) or (e) as ideal parabolic flow condition. Both ideal plug flow inlet and ideal parabolic flow inlet conditions are discussed in this study. The inlet flow condition is also affected by the rheology of electrolyte. For example, the plug flow inlet condition will occur when electrolyte has a high viscosity (e.g. electrolyte containing particles or suspension or slurry or semi-solid electrolyte) [9,10,46-52]. High viscosity electrolyte can be considered as the non-Newtonian flow and used in the electrochemical flow capacitor (EFC). Also, the shear thinning behavior can be observed in the suspension or slurry or semi-solid non-Newtonian electrolyte flow. This transport phenomenon is related to the relationship between shear rate and electrolyte viscosity. Under the condition of increasing viscosity with decreasing shear rate, the shear thinning behavior occurs. Vice versa, the shear thickening behavior occurs under the condition of increasing viscosity with increasing shear rate. The discussions of the non-Newtonian electrolyte flow are beyond the scope of this work. 


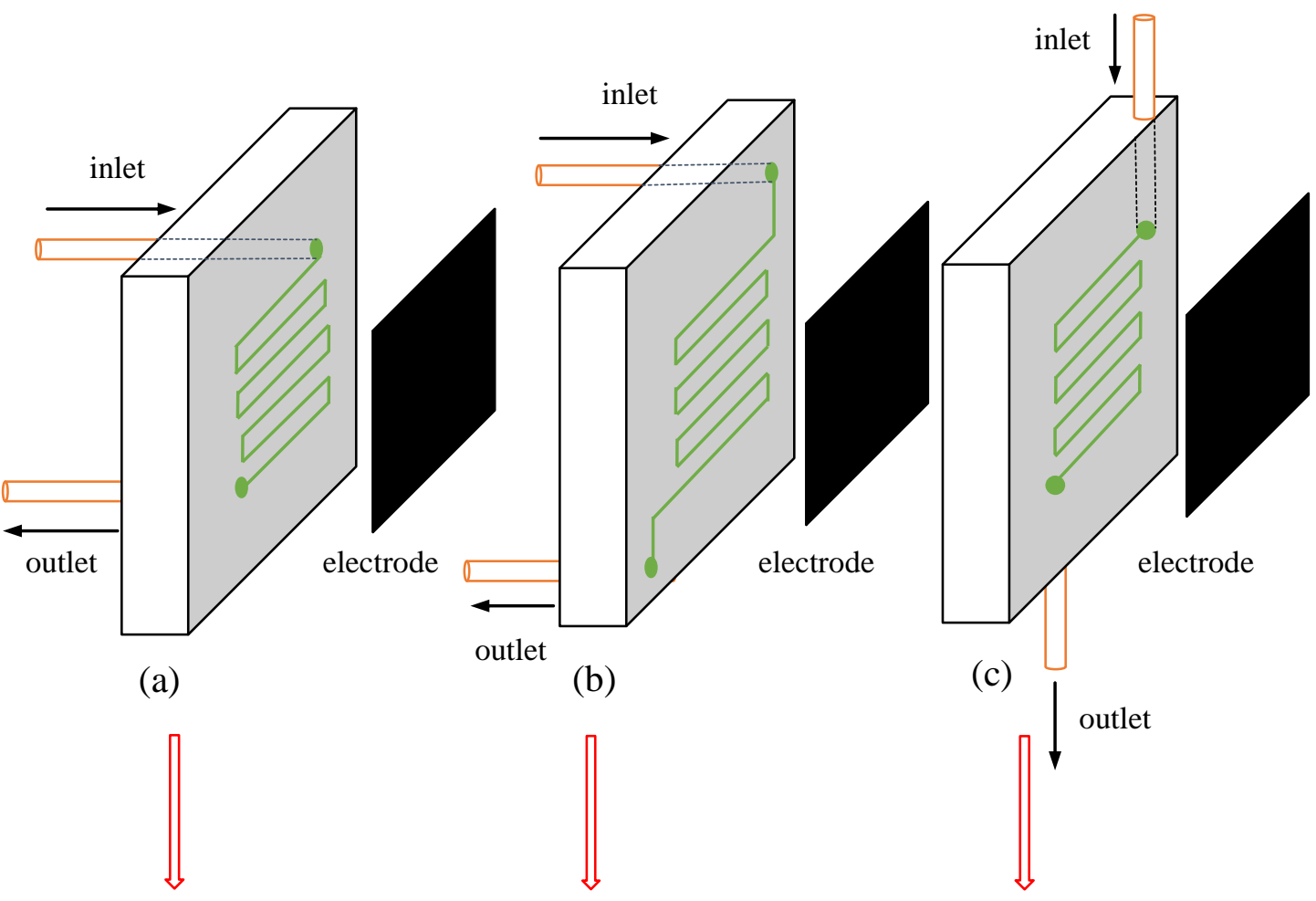

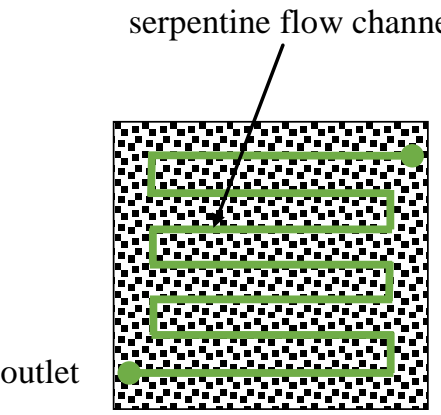

(d)

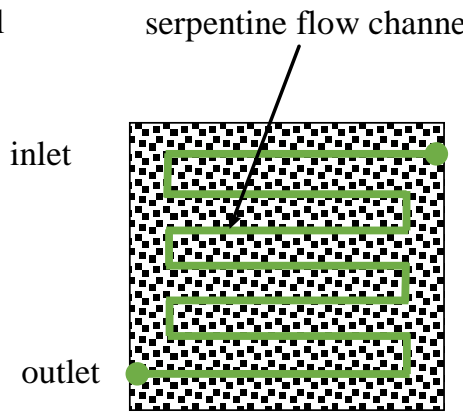

(e)

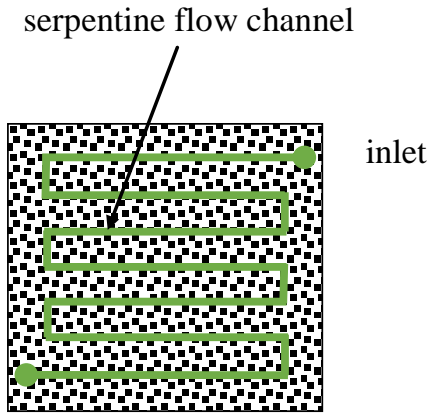

(f)

Fig. 3. Schematic diagram of possible electrolyte flow types in RFBs with serpentine flow field:

(a) incoming electrolyte flow is perpendicular to serpentine flow field without head flow channel;

(b) incoming electrolyte flow is perpendicular to serpentine flow field with a head flow channel;

(c) incoming electrolyte flow is parallel to serpentine flow field; (d) two-dimensional flow channel-porous electrode view of (a); (e) two-dimensional flow channel-porous electrode view of (b) and (f) two dimensional flow channel-porous electrode view of (c) 


\section{Results and Discussions}

\subsection{Flow patterns}

The evolutions of non-dimensional $u_{f}{ }^{*}\left(u_{f} u_{i n}{ }^{-1}\right)$ and $\left\langle u_{p}\right\rangle^{*}\left(\left\langle u_{p}\right\rangle u_{i n}{ }^{-1}\right)$ given in Table 1 along the normalized longitudinal $Y^{*}\left(Y\left(t_{f}+t_{p}\right)^{-1}\right)$ from -0.29 to 0.71 for four different $X^{*}\left(X L^{-1}\right): 0,0.1$, 0.2 and 0.7 as the flow develops from ideal parabolic flow type entrance to developing (the gradient of velocity along $X^{*}\left(X L^{-1}\right)$ is not zero and in the progress of approaching to be zero) and fully developed (the gradient of velocity along $X^{*}\left(X L^{-1}\right)$ is zero) regions are shown in Fig. 4. To clearly visualize the electrolyte flow through the porous electrode, the permeability of $9.7 \times 10^{-9} \mathrm{~m}^{2}$ is applied. The normalized average velocity $u_{f}^{*}$ avg defined in Eq. (5) $[22,23]$ decreases from 1 to 0.94 while $\left\langle u_{p}\right\rangle{ }^{*}$ avg defined in Eq. (6) [22,23] shows an opposite tendency that increases from 0 to 0.15 as the fully developed region is approached.

$$
\begin{aligned}
& \left(u_{f}^{*}{ }_{\text {avg }}\right)_{X^{*}}=\frac{t_{f}+t_{p}}{t_{f}} \int_{0}^{\frac{t_{f}}{t_{f}+t_{p}}} u_{f}^{*}\left(X^{*}, Y^{*}\right) d Y^{*} \\
& \left(\left\langle u_{p}\right\rangle_{\text {avg }}^{*}\right)_{X^{*}}=\frac{t_{f}+t_{p}}{t_{p}} \int_{-\frac{t_{p}}{t_{f}+t_{p}}}^{0}\left\langle u_{p}\right\rangle^{*}\left(X^{*}, Y^{*}\right) d Y^{*}
\end{aligned}
$$




\subsection{Flow and pressure distributions}

The flow distributions under the conditions of ideal plug flow inlet and ideal parabolic flow inlet are studied. In our previous publication (Ref. [23]), a shoot (means a dramatic increase) was found in the flow velocity distributions in the porous layer with a small $X^{*}\left(X L^{-1}\right)$ when the ideal plug flow inlet condition was applied. A possible reason is that the interface forwarding electrolyte flow momentum through the flow channel forces the electrolyte with a fast penetration near to the left wall ( $B C \# 5$, see Fig. 2 (a)) of the porous electrode at the interface under the ideal plug flow inlet condition. Nevertheless, the shoot disappears under the ideal parabolic flow inlet condition. The normalized flow velocity $\left\langle u_{p}\right\rangle^{*}\left(\left\langle u_{p}\right\rangle u_{i n}{ }^{-1}\right)$ distributions along $X^{*}\left(X L^{-1}\right)$ for different $Y^{*}\left(Y\left(t_{f}+t_{p}\right)^{-1}\right)$ in the porous electrode is shown in Fig. 5. It is found that almost no shoot occurs in Fig. 5 (b) under the ideal parabolic flow inlet condition. A 
possible explanation is that the initial entrance interface velocity is zero, and no large flow momentum will drag the electrolyte flow in the flow channel with a sharp flow penetration into the porous electrode under the ideal parabolic flow inlet condition.

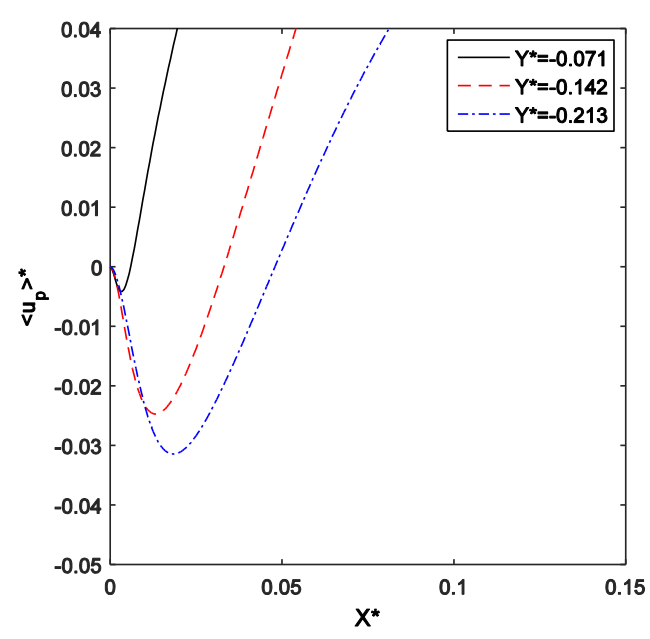

(c)

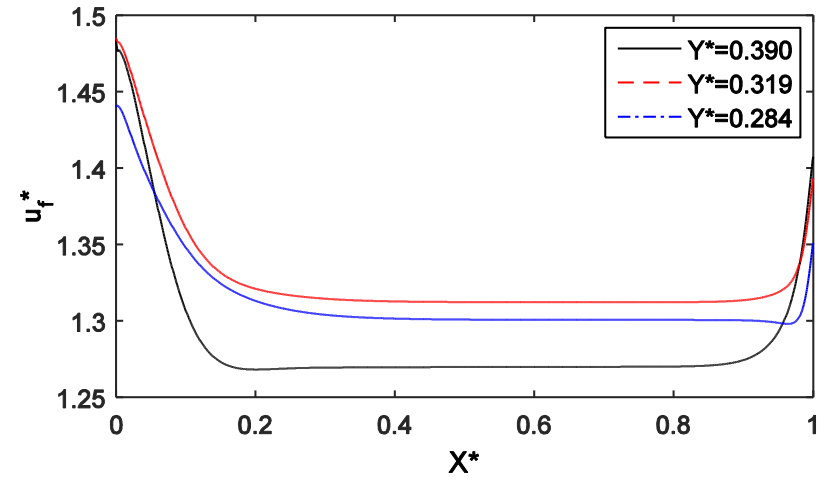

(a)

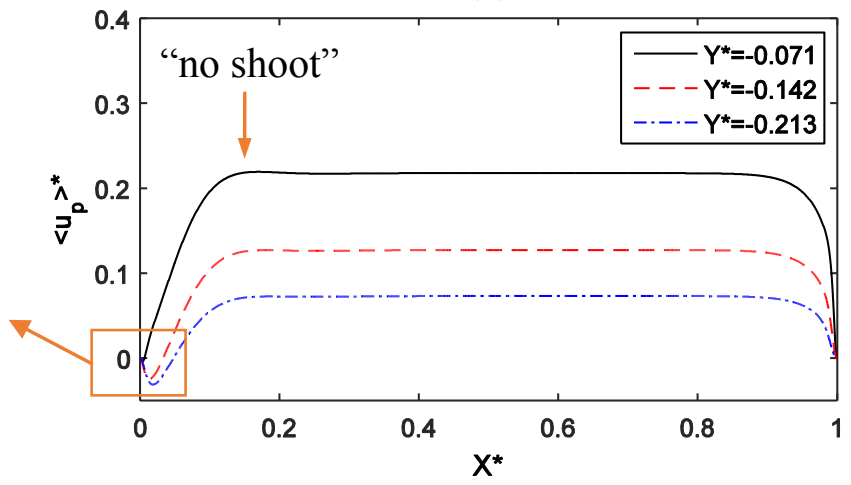

(b)

Fig. 5. The trend of normalized $u_{f}{ }^{*}\left(u_{f} u_{i n}{ }^{-1}\right)$ and $\left\langle u_{p}\right\rangle^{*}\left(\left\langle u_{p}\right\rangle u_{i n}{ }^{-1}\right)$ with $X^{*}\left(X L^{-1}\right)$ from 0 to 1 at $\operatorname{six} Y^{*}\left(Y\left(t_{f}+t_{p}\right)^{-1}\right): 0.390,0.319,0.284,-0.071,-0.142$ and -0.213 in the flow channel and porous electrode under ideal parabolic flow inlet condition ("no shoot") 


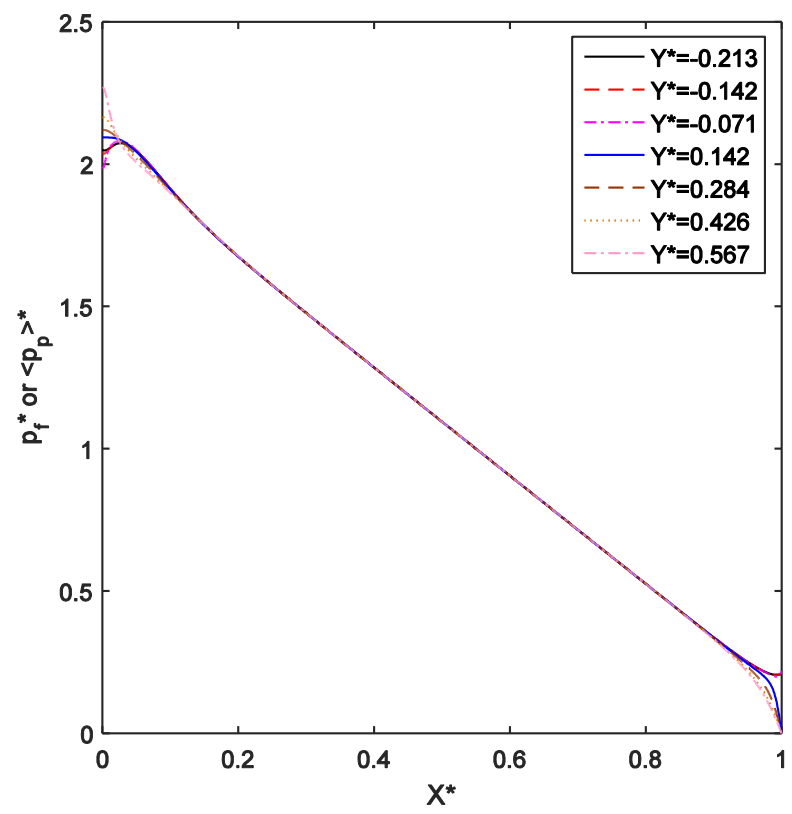

(a)

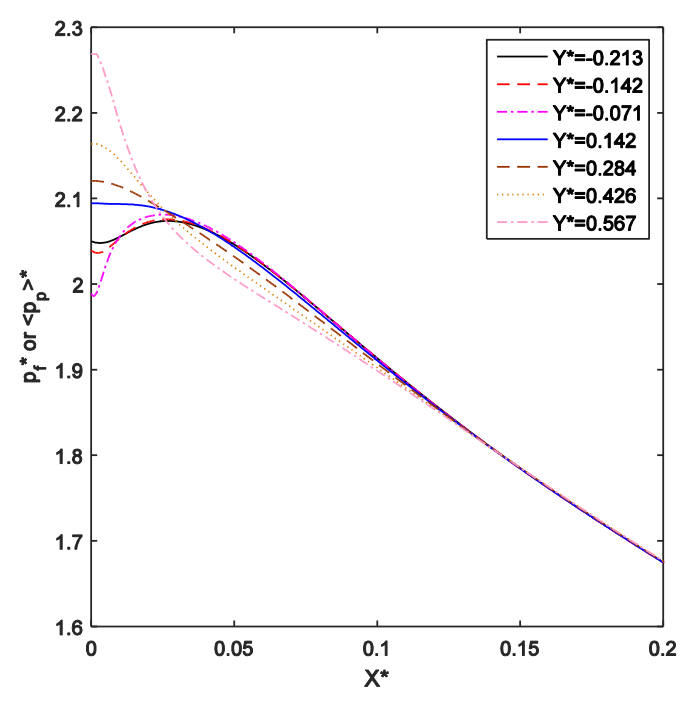

(b)

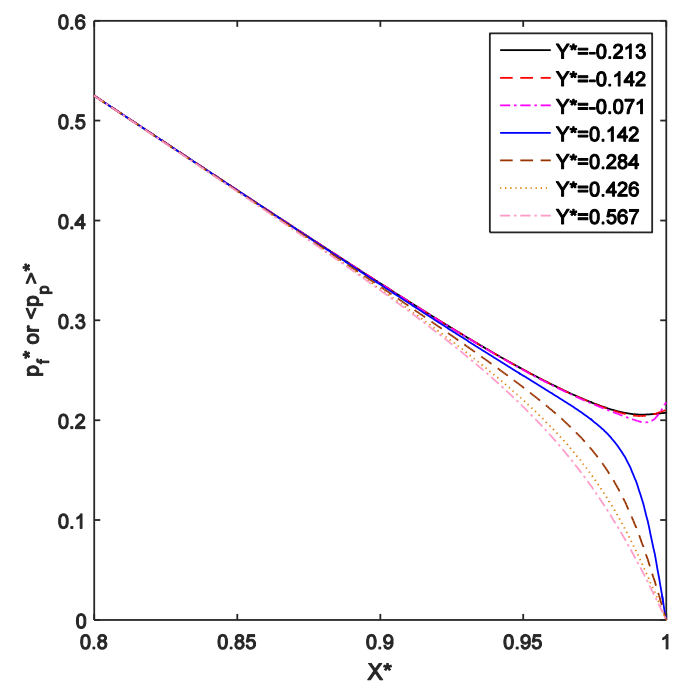

(c)

Fig.6. Dimensionless $P_{f}{ }^{*}\left(P_{f}\left(\rho u_{i n}{ }^{2}\right)^{-1}\right)$ and $\left\langle P_{p}\right\rangle^{*}\left(\left\langle P_{p}\right\rangle\left(\rho u_{i n}{ }^{2}\right)^{-1}\right)$ distributions along $X^{*}\left(X L^{-1}\right)$ at seven $Y^{*}\left(Y\left(t_{f}+t_{p}\right)^{-1}\right):-0.213,-0.142,-0.071,0.142,0.284,0.426$ and $0.567 ;(\mathrm{b})$ and (c) are the corresponding enlarged local curves of (a) 
The shoot phenomenon also can be explained through the pressure distributions as shown in Fig. 6. The normalized pressure distribution along $X^{*}\left(X L^{-1}\right)$ in the flow channel and the porous electrode at seven different $Y^{*}\left(Y\left(t_{f}+t_{p}\right)^{-1}\right)$ as Reynolds number is 91.5 under the ideal plug flow inlet condition is presented. Fig. 6 (b) and (c) are the enlarged local curves of Fig. 6 (a). As $X^{*}$ (X $\left.L^{-1}\right)$ ranges from $\sim 0.15$ to $\sim 0.85$, the non-dimensional $P_{f}^{*}\left(P_{f}\left(\rho u_{i n}{ }^{2}\right)^{-1}\right)$ is almost equal to $\left\langle P_{p}\right\rangle^{*}$ $\left(<P_{p}>\left(\rho u_{i n}{ }^{2}\right)^{-1}\right)$, where the fully developed regime is approached. $P_{f}^{*}\left(P_{f}\left(\rho u_{i n}{ }^{2}\right)^{-1}\right)$ is larger than $\left\langle P_{p}>^{*}\left(<P_{p}>\left(\rho u_{i n}{ }^{2}\right)^{-1}\right)\right.$ when $X^{*}\left(X L^{-1}\right)$ is from 0 to $\sim 0.03$ at the beginning of the flow, then electrolyte fluid is driven into the porous electrode from the flow channel. When $X^{*}\left(X L^{-1}\right)$ is from $\sim 0.03$ to $\sim 0.15, P_{f}^{*}\left(P_{f}\left(\rho u_{i n}{ }^{2}\right)^{-1}\right)$ is slightly smaller than $\left\langle P_{p}\right\rangle^{*}\left(\left\langle P_{p}\right\rangle\left(\rho u_{i n}{ }^{2}\right)^{-1}\right)$, some flow is forced back into the flow channel from the porous electrode. At the end of the flow, the pressure in the porous layer is larger than in the flow channel as shown in Fig. 6 (c), and it can drive the flow back into the flow channel from the porous electrode. Nevertheless, no electrolyte flow is driven out at the beginning of the flow under the ideal parabolic flow inlet condition. Fig. 5 also reveals that some back flow occurs and it can be explained through the non-dimensional pressure distributions as shown in Fig. 5.

\subsection{Interface flow and volumetric flow penetration}

The distributions of flow velocity $v$ along the $Y$ direction at the interface between the flow channel and porous electrode under the ideal plug flow and ideal parabolic flow inlet conditions are shown in Fig. 7 (a) and (b), respectively. At most part of the interface between the flow channel and porous electrode, except at the beginning and end of the electrolyte flow, $v$ velocity is almost zero. The reason is that the flow entrance length under the ideal plug flow inlet condition is $\sim 0.4 \mathrm{~cm}$ to $0.5 \mathrm{~cm}$ based on the initial inlet mean velocity of $33.3 \mathrm{~cm} \mathrm{~s}^{-1}$ or initial entrance volumetric flow rate of $20 \mathrm{~cm}^{3} \mathrm{~min}^{-1}$. The length of the flow channel or porous electrode 
is $2 \mathrm{~cm}$. Thus, $\sim 75 \%$ to $80 \%$ of flow region in the flow channel and porous electrode are in the fully developed regime. Under this case, there is no pressure difference between the flow channel and porous electrode. Flow penetration will not occur at the interface without pressure driven force as the fully developed regime is approached.
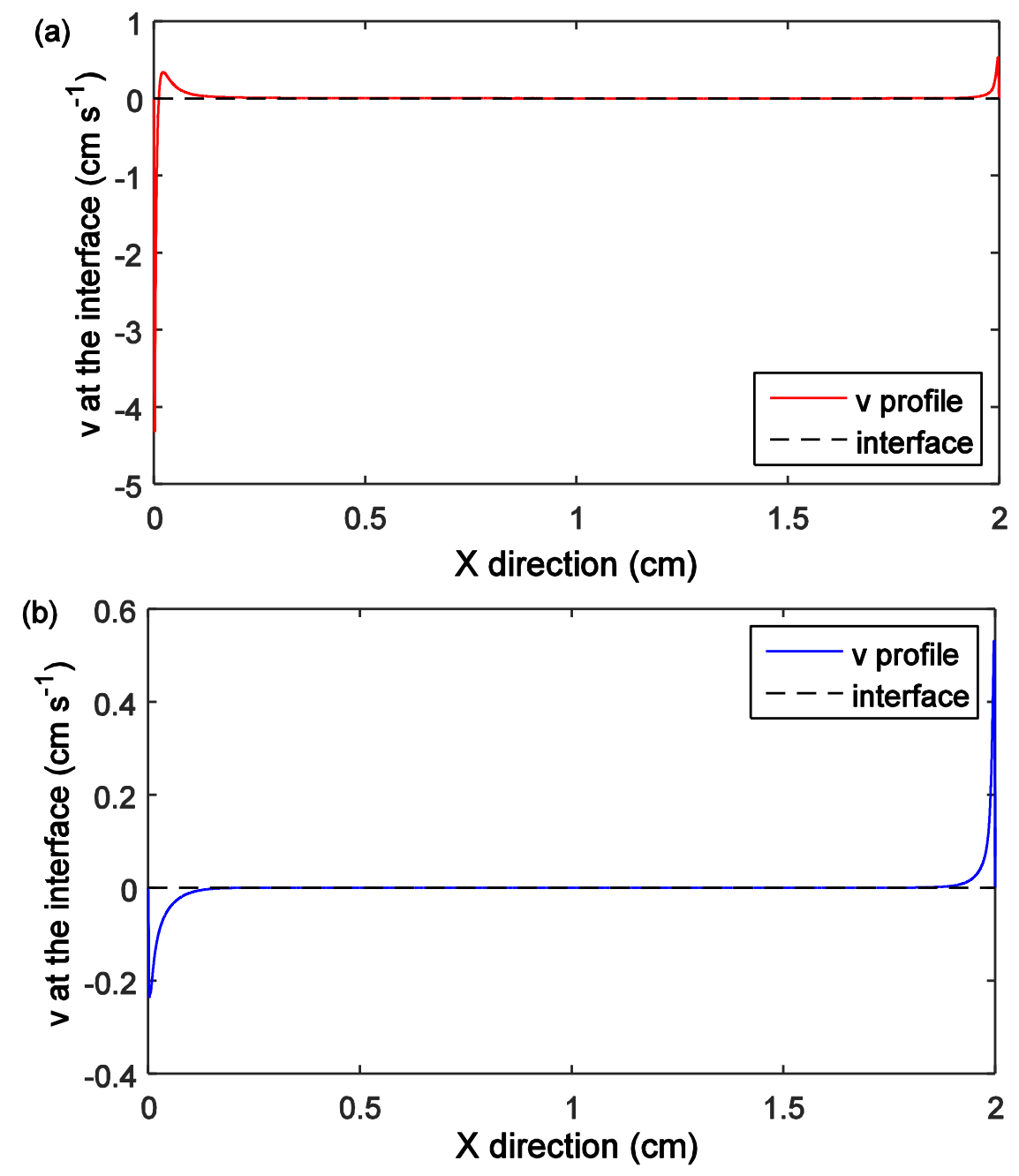

Fig. 7. $v$ velocity distributions at the interface between the flow channel and porous electrode: (a) ideal plug flow inlet condition and (b) ideal parabolic flow inlet condition (single layer of $10 \mathrm{AA}$ carbon fiber paper, $Q_{i n}=20 \mathrm{~cm}^{3} \mathrm{~min}^{-1}$ ) 
For the segment of one flow channel over porous electrode, the interfacial flow velocity as shown in Fig. 7 yields the volumetric flow penetration through the electrode

$$
\left(Q_{p}\right)_{f c}=\left|w_{p} \int_{0}^{L}\left(v_{p}^{-}\right)_{\Sigma_{f p}} d X\right|
$$

Where, $L$ is the length of interface between the flow channel and porous electrode $(2 \mathrm{~cm}), w_{p}$ is the width of the porous electrode $(0.1 \mathrm{~cm})$ and $\left(v_{p}{ }^{-}\right)_{\Sigma_{f p}}$ is the negative $v$ velocity (negative value means that electrolyte penetrates into the interface and positive value means that electrolyte penetrates out of the interface) as shown in Fig. 7. More importantly, the landing/rib with corner channel advection can force much more volumetric flow penetration through the porous electrode. The flow penetration under the advection effect of landing/rib with corner channel can be estimated (see appendix section)

$\left(Q_{p}\right)_{l c} \sim \frac{L}{r}\left(Q_{p}\right)_{f c}$

Where, $r$ is the distance between the adjacent flow channels or length of landing/rib and $L$ is the length of flow channel. In the experimental measurement, $r$ and $L$ is corresponding to be $0.1 \mathrm{~cm}$ and $2 \mathrm{~cm}$. It is clear from Eq. (8) that the order magnitude of volumetric flow penetration through the porous electrode under the advection of landing/rib with corner channel is $\sim 20$ times to be the one under the flow channel advection. The total volumetric flow penetration through the porous electrode under both advections by flow channel and landing/rib with corner channel is estimated (see appendix section) 
$\left(Q_{p}\right)_{t o t}=\left(Q_{p}\right)_{f c}+\left(Q_{p}\right)_{l c} \sim\left(1+\frac{L}{r}\right)\left(Q_{p}\right)_{f c}$

The total volumetric flow penetration through the porous electrode can be related to the dimensions of the flow cell (e.g. length, width and thickness of flow channel and porous electrode), properties of electrolyte (e.g. density and dynamic viscosity), properties of porous electrode (e.g. porosity and permeability), initial ion concentration and entrance volumetric flow rate (or entrance mean linear velocity).

\subsection{Discussions on estimated maximum current density}

The second law of Faraday's electrolysis and volumetric flow balance through the porous electrode yield that the maximum current density can be achieved in RFBs with flow field design limited by the $100 \%$ amount of electrolyte reactant consumption through the porous electrode under both flow channel and landing/rib with corner channel advections yields

$i_{\max }=\frac{n F c\left(Q_{p}\right)_{t o t}}{\left(w_{f c}+r\right) L}$

Where, $n$ is the number of electron transferred in the chemical reactions $(n=1$, vanadium flow battery), $F$ is the Faraday constant $\left(96,485 \mathrm{C} \mathrm{mol}^{-1}\right), c$ is the bulk concentration $\left(0.001 \mathrm{~mol} \mathrm{~cm}^{-3}\right)$, $\left(Q_{p}\right)_{t o t}$ is the total volumetric flow rate through the porous electrode as shown in Eq. (9), $w_{f c}$ is the width of the flow channel, $r$ is the distance between adjacent flow channels or length of landing/rib and $L$ is the length of flow channel. Based on the permeability of $2.31 \times 10^{-6} \mathrm{~cm}^{2}$ estimated by Kozeny-Carman model [36,37], the corresponding theoretical maximum current density estimated by Eq. (10) is $7,917 \mathrm{~mA} \mathrm{~cm}^{-2}$ (vs. experimental result of $400 \mathrm{~mA} \mathrm{~cm}^{-2}$, [20]) 
and $15,204 \mathrm{~mA} \mathrm{~cm}^{-2}$ (vs. experimental result of $\sim 750 \mathrm{~mA} \mathrm{~cm}^{-2},[14]$ ) for one layer and three layers of SGL 10AA carbon paper electrode. However, Weber et al. [1] $\left(k=2 \times 10^{-7} \mathrm{~cm}^{2}\right)$ and Gostick et al. [35] $\left(k=1 \times 10^{-7} \mathrm{~cm}^{2}\right)$ pointed out that the permeability for the typical carbon paper electrode could be the order of $10^{-11} \mathrm{~m}^{2}$. It is likely that the permeability estimated by KozenyCarman is over-estimated. If the permeability of $1 \times 10^{-7} \mathrm{~cm}^{2}$ is applied, then the corresponding maximum current density estimated by Eq. (10) is $343 \mathrm{~mA} \mathrm{~cm}^{-2}$ and $658 \mathrm{~mA} \mathrm{~cm}^{-2}$ for one layer and three layers of SGL 10AA carbon paper electrode. It is clear that the theoretical maximum current density achieved is sensitive to the value of permeability. The discrepancy between the theoretical maximum current density and experimental value can be caused by the accuracy of parameters (such as permeability, dynamic viscosity, etc.) as shown in Table 1. The full serpentine flow dynamic pattern in the three-dimensional model of serpentine flow channel over the porous electrode will be explored in the future. The further work on mathematical optimizations of flow batteries with different flow field designs is still needed. In this work, we explore flow penetration and its related maximum current density in vanadium flow battery with flow field design over carbon paper electrode. Compared with classic one without flow field design through the carbon felts, two possible benefits brought by using flow field design within improving electrochemical performance: (1) lower ohmic loss in carbon paper electrode (e.g. hundred microns) compared with carbon felts (e.g. several millimeters) and (2) stronger mass transfer through the electrode layer from the flow field caused by the forced convection. Nevertheless, one significant drawback for the flow cell with flow field manifolds is the issue of non-uniform flow reactant distribution within the electrode. A "dead zone" for electrolyte flow always occurs at the flow cell with a bad flow field design. Thus, the optimizations of flow distributions for flow cells with flow field designs by mathematical modeling approaches are 
desired. The understanding of transport mechanism in the flow cell can be achieved through both experiments and mathematical modeling. Both merits and demerits exist in modeling analysis. Although it is always easier to construct a modeling framework, the more questionable computational results need to be validated with experimental data. Also, the mathematical approach is not necessarily to be quicker compared with experiments. For example, the simplified mathematical model can be far away from the practical designs with non-uniformities of flow distributions and poor scale-up capabilities. From this aspect, developing a good multiphysics model to match reasonably with desirable and important experiments can cost more labor efforts. Thus, more benefits can be achieved through integrating computational modeling with experimental studies: e.g. flow visualization, pressure drop vs. flow measurement and electrochemical performance measurement.

\section{Concluding remarks}

A simplified two-dimensional mathematical model is developed to study the electrolyte flow patterns and volumetric flow penetrations in vanadium flow battery with a single segment of flow channel over the carbon fiber paper electrode layered system. It is found that the interface flow distributions is different under the ideal plug flow inlet and ideal parabolic flow inlet conditions and this is caused by non-linear pressure behaviors in the flow channel and porous electrode at the beginning and end of flow. The mathematical model of volumetric flow penetration through the integration of interface flow velocity reveals that the volumetric flow penetration within the porous electrode by the flow channel advection is equal under both ideal plug flow and ideal parabolic flow inlet conditions. Flow penetrations under both advection effects of flow channel and landing/rib with corner channel are estimated. The maximum current density achieved in the flow battery can be predicted based on the $100 \%$ amount of electrolyte 
flow reactant consumption through the porous electrode beneath both flow channel and landing/rib with corner channel. It is found that the corresponding maximum current density estimated is sensitive to the value of permeability. Based on a proper permeability, the theoretical maximum current density have reasonable agreement with experimental results of vanadium flow battery with one and three layers SGL 10AA carbon paper electrode.

\section{Acknowledgements}

This work is partially supported by the flow battery project (DE-AR0000352) funded from Department of Energy (DOE) of the United States. We thank Dr. D.L. Feke and Dr. P. Barnhart from Case Western Reserve University for discussing the boundary conditions of ideal plug flow and ideal parabolic flow inlet boundary conditions. We thank Dr. N.C. Hoyt from Case Western Reserve University for give the suggestions on the volumetric flow rate through the porous electrode. We gratefully acknowledge the helpful advice from Dr. A.Z. Weber from Lawrence Berkeley National Laboratory and Dr. M.M. Mench from University of Tennessee at Knoxville.

\section{Appendix A}

The advection effect of landing/rib with corner channel on the flow penetration in the actual three-dimensional model is incorporated in this two-dimensional model through the scaling analysis. The derivation processes of Eqs. (8) and (9) are explained in this appendix section. The serpentine flow field over electrode layer can be considered as several periodic segments of two adjacent flow channels (\#1 and \#2), one landing/rib with one corner channel over the electrode layer. This is illustrated in Fig. A.1: (a) \#1 flow channel over the electrode; (b) one landing/rib with one corner channel over the electrode and (c) \#2 adjacent flow channel over the electrode. The mathematical derivation processes of average velocity and volumetric flow rate through the 
electrode are described. For Fig. A.1 (a), the average flow velocity and volumetric flow rate through the porous electrode based on Darcy's law yield

$$
\left\langle u_{p}\right\rangle_{f c, 1}=-k \nabla\left(P_{p}\right) / \mu \sim k\left(\left(P_{p}\right)_{1}-\left(P_{p}\right)_{2}\right) / \mu L_{p}
$$

$\left(Q_{p}\right)_{f c, 1}=\left\langle u_{p}\right\rangle_{f c, 1} w_{p} t_{p} \sim k w_{p} t_{p}\left(\left(P_{p}\right)_{1}-\left(P_{p}\right)_{2}\right) / \mu L_{p}$

Where, $k$ is the permeability of porous electrode, $\mu$ is the electrolyte dynamic viscosity, $w_{p}$ is the width of porous electrode, $t_{p}$ is the thickness of porous electrode and $L_{p}$ is the length of porous electrode.

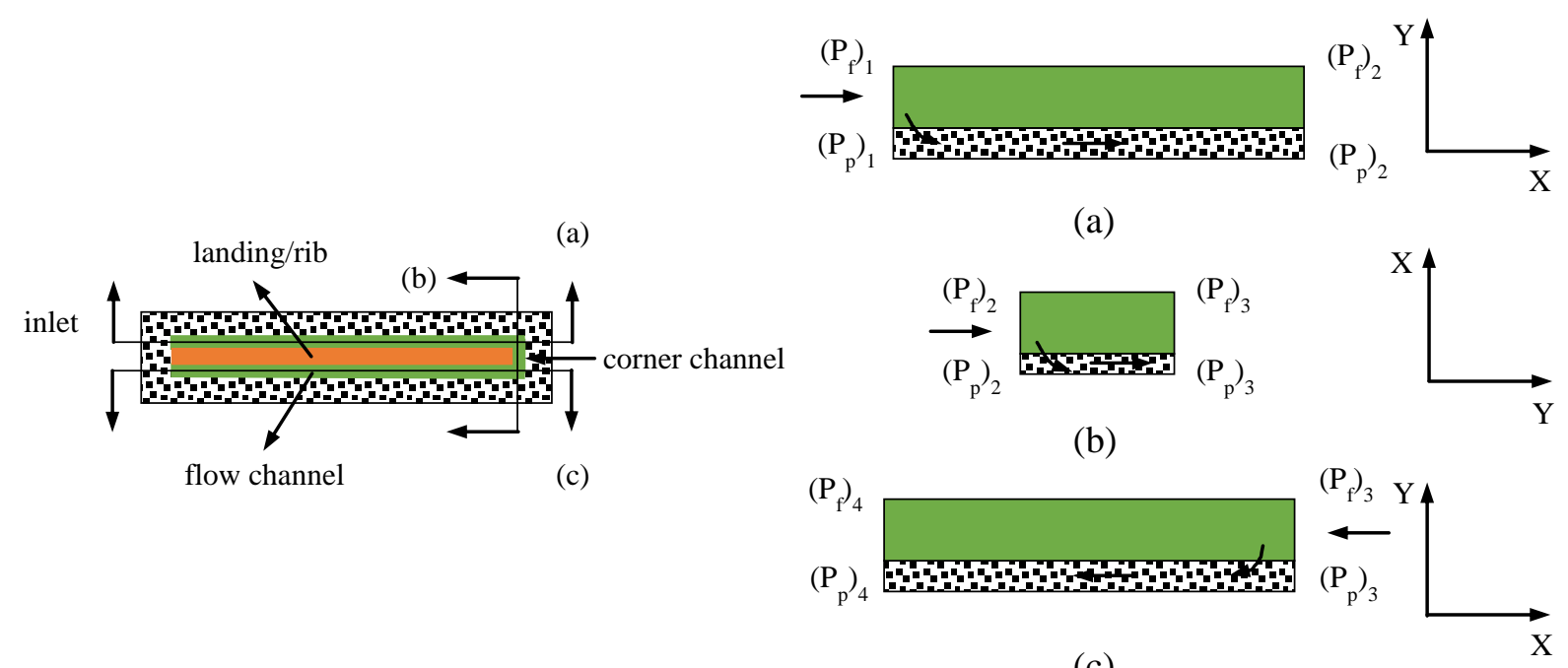

(c)

Fig. A.1 Schematic diagram of flow penetration through the porous electrode under the advection effect of landing/rib with corner channel: (a) one flow channel (\#1) over the electrode; (b) one landing/rib with one corner channel over the electrode and (c) adjacent flow channel (\#2) over the electrode. 
For Fig. A.1 (b), the average flow velocity and volumetric flow rate through the electrode beneath the landing/rib and corner channel

$$
\begin{aligned}
& \left\langle v_{p}\right\rangle_{l c}=-k \nabla\left(P_{p}\right) / \mu \sim k\left(\left(P_{p}\right)_{2}-\left(P_{p}\right)_{3}\right) / \mu r \\
& \left(Q_{p}\right)_{l c}=\left\langle v_{p}\right\rangle_{l c} L_{p} t_{p} \sim k L_{p} t_{p}\left(\left(P_{p}\right)_{2}-\left(P_{p}\right)_{3}\right) / \mu r
\end{aligned}
$$

Where, $r$ is the distance between adjacent flow channels (\#1 and \#2). For Fig. A.1 (c), the average flow velocity and volumetric flow rate through the porous electrode

$$
\begin{aligned}
& \left\langle u_{p}\right\rangle_{f c, 2}=-k \nabla\left(P_{p}\right) / \mu \sim k\left(\left(P_{p}\right)_{3}-\left(P_{p}\right)_{4}\right) / \mu L_{p} \\
& \left(Q_{p}\right)_{f c, 2}=\left\langle u_{p}\right\rangle_{f c, 2} w_{p} t_{p} \sim k w_{p} t_{p}\left(\left(P_{p}\right)_{3}-\left(P_{p}\right)_{4}\right) / \mu L_{p}
\end{aligned}
$$

In this simulation with a small Reynolds number of 91.5, laminar flow regime is approached as the electrolyte flow through the flow channel and porous electrode. The pressure in the laminar flow always exhibits a linear behavior and this also can be demonstrated by Fig. (6): the pressure in most part region of flow channel and porous electrode is linear. The pressure gradient in (a), (b) and (c) as shown in Fig. A.1 can be approximated to be equal

$$
\left(\left(P_{p}\right)_{1}-\left(P_{p}\right)_{2}\right) / L_{p} \sim\left(\left(P_{p}\right)_{2}-\left(P_{p}\right)_{3}\right) / r \sim\left(\left(P_{p}\right)_{3}-\left(P_{p}\right)_{4}\right) / L_{p}
$$


Thus, Eqs. (A.2), (A.4), (A.6), (A.7) yield

$\left(Q_{p}\right)_{f c, 1} \sim\left(Q_{p}\right)_{f c, 2} \sim\left(Q_{p}\right)_{l c} r / L_{p}$ 


\section{References}

[1] A.Z. Weber, M.M. Mench, J.P. Meyers, P.N. Ross, J.T. Gostick, Q. Liu, J. Appl.

Electrochem. 41 (2011) 1137-1164.

[2] W. Wang, Q. Luo, B. Li, X. Wei, L. Li, Z. Yang, Adv. Funct. Mater. 23 (2013) 970-986.

[3] A. Parasuraman, T.M. Lim, C. Menictas, M. Skyllas-Kazacos, Electrochim. Acta 101 (2013)

$27-40$.

[4] P. Alotto, M. Guarnieri, F. Moro, Renew. Sust. Energy Rev. 29 (2014) 325-335.

[5] M. Skyllas-Kazacos, M. Rychcik, R.G. Robins, A.G. Fane, M.A. Green, J. Electrochem. Soc. 133 (1986) 1057-1058.

[6] Z. Li, W. Dai, L. Yu, J. Xi, X. Qiu, L. Chen, J. Power Sources 257 (2014) 221-229.

[7] L.H. Thaller, "Redox flow cell energy storage systems", Department of Energy, Washington, DC, DOE/NASA/1002-79/3; National Aeronautics and Space Administration: Washington, DC, NASA TM-79143 (1979).

[8] L.W. Hruska, R.F. Savinell, J. Electrochem. Soc. 128 (1981) 18-25.

[9] T.J. Petek, N.C. Hoyt, R.F. Savinell, J.S. Wainright, J. Electrochem. Soc. 163 (2016) A5001 A5009.

[10] M. Duduta, B. Ho, V.C. Wood, P. Limthongkul, V.E. Brunini, W.C. Carter, Y.M. Chiang, Adv. Energy Mater. 1 (2011) 511-516.

[11] L. Li, S. Kim, W. Wang, M. Vijayakumar, Z. Nie, B. Chen, J. Zhang, G. Xia, J. Hu, G. Graff, J. Liu, Z. Yang, Adv. Funct. Mater. 1 (2011) 394-400.

[12] A.A. Shinkle, A.E.S. Sleightholme, L.D. Griffith, L.T. Thompson, C.W. Monroe, J. Power Sources 206 (2012) 490-496. 
[13] C. Flox, M. Skoumal, J. Rubio-Garcia, T. Andreu, J.R. Morante, Appl. Energy 109 (2013) 344-351.

[14] A.A. Shah, R. Tangirala, R. Singh, R.G.A. Wills, F.C. Walsh, J. Electrochem. Soc. 158 (2011) A671-A677.

[15] K.W. Knehr, E. Agar, C.R. Dennison, A.R. Kalidindi, E.C. Kumbur, J. Electrochem. Soc. 159 (2012) A1446-A1459.

[16] J. Newman, C.W. Tobias, J. Electrochem. Soc. 109 (1962): 1183-1191.

[17] J. Newman, W. Tiedemann, AlChE Journal 21 (1975): 25-41.

[18] A.A. Shah, M.J. Watt-Smith, F.C. Walsh, Electrochim. Acta 53 (2008) 8087-8100.

[19] D. You, H. Zhang, J. Chen, Electrochim. Acta 54 (2009) 6827-6836.

[20] D.S. Aaron, Q. Liu, Z. Tang, G.M. Grim, A.B. Papandrew, A. Turhan, T.A. Zawodzinski, M.M. Mench, J. Power Sources 206 (2012) 450-453.

[21] D. Aaron Z. Tang, A.B. Papandrew, T.A. Zawodzinski, J. Appl. Electrochem. 41 (2011) 1175-1182.

[22] X. Ke, "CFD studies on mass transport in redox flow batteries", Master Thesis, Case Western Reserve University, United States, 2014 (https://etd.ohiolink.edu).

[23] X. Ke, J.I.D. Alexander, J.M. Prahl, R.F. Savinell, J. Power Sources 270 (2014) 646-657.

[24] X. Ke. J.I.D. Alexander, J.M.Prahl, R.F. Savinell, J. Power Sources 288 (2015) 308-313.

[25] T.J. Latha, S. Jayanti, J. Appl. Electrochem. 44 (2014) 995-1006.

[26] S. Kumar, S. Jayanti, J. Power Sources 307 (2016) 782-787.

[27] W. Merzkirch, "Flow Visualization", Book, $2^{\text {nd }}$ Edition, Academic Press, Inc., United States, 1987.

[28] P.V. Danckwerts, Chem. Eng. Sci. 2 (1953) 1-13. 
[29] C. Ponce-de-León, G.W. Reade, I. Whyte, S.E. Male, F.C. Walsh, Electrochim. Acta 52 (2007) 5815-5823.

[30] C. Ponce-de León, I. Whyte, G.W. Reade, S.E. Male, F.C. Walsh, Aust. J. Chem. 61 (2008) 797-804.

[31] P. Leung, X. Li, C. Ponce de-Léon, L. Berlouis, C.T.J. Low, F.C. Walsh, RSC Adv. 2 (2012) $10125-10156$.

[32] C. Ponce-de-León, A. Frías-Ferrer, J. González-Garcia, D.A. Szánto, F.C. Walsh, J. Power Sources 160 (2006) 716-732.

[33] G. Kear, A.A. Shah, F.C. Walsh, Inter. J. Energ. Res. 36 (2012) 1105-1120.

[34] M.J. Watt-Smith, P. Ridley, R.G.A. Wills, A.A. Shah, F.C. Walsh, J. Chem. Tech. Biotech. 88 (2013) 126-138.

[35] J.T. Gostick, M.W. Fowler, M.D. Pritzker, M.A. Ioannidis, L.M. Behra, J. Power Sources 162 (2006) 228-238.

[36] P.C. Carman, Trans. Inst. Chem. Eng. Lond. 15 (1937) 150-166.

[37] J. Kozeny, Stizungsber Akad. Wiss. Wien. 136 (1927) 271-306.

[38] P. Trogadas, O.O. Taiwo, B. Tjaden, T.P. Neville, S. Yun, J. Parrondo, V. Raman, M.O.

Coppens, D.J.L. Brett, P.R. Shearing, Electrochem. Commun. 48 (2014) 155-159.

[39] I. Derr, M. Bruns, J. Langer, A. Fetan, J. Melke, C. Roth, J. Power Sources 325 (2016) 351359.

[40] K. Vafai, R. Thiyagaraja, Int. J. Heat and Mass Transfer 30 (1987) 1391-1405.

[41] S.J. Kim, C.Y. Choi, Int. J. Heat and Mass Transfer 39 (1996) 319-329.

[42] D. Poulikakos, M. Kazmierczak, J. Heat Transfer 109 (1987) 653-662. 
[43] M. Ehrhardt, “An Introduction to Fluid-Porous Interface Coupling, http://www.math.uniwuppertal.de", last accessed: May 2014.

[44] V. Laptev, "Numerical Solution of Coupled Flow in Plain and Porous Media", Ph.D. Thesis, University of Kaiserslautern, 2003.

[45] J.A. Schetz, A.E. Fuhs, "Fundamentals of Fluid Mechanics", Book, $3^{\text {rd }}$ Edition, John Wiley \& Sons, United States, 1999.

[46] K.C. Smith, Y.M. Chiang, W.C Carter, J. Electrochem. Soc. 161 (2014) A486-A496.

[47] V.E. Brunini, Y.M. Chiang, W.C. Carter, Electrochim. Acta 69 (2012) 301-307.

[48] K.C. Smith, V.E. Brunini, Y. Dong, Y.M. Chiang, W.C. Carter, Electrochim. Acta 147 (2012) 460-469.

[49] J.W. Campos, M. Beidaghi, K.B. Hatzell. C.R. Dennison, B. Musci, V. Presser, E.C. Kumbur, Y. Gogotsi, Electrochim. Acta 98 (2013) 123-130.

[50] K.B. Hatzell, M. Beidaghi, J.W. Campos, C.R. Dennison, E.C. Kumbur, Y. Gogotsi, Electrochim. Acta 111 (2013) 888-897.

[51] C.R. Dennison, M. Beidaghi, K.B. Hatzell, J.W. Campos, Y. Gogotsi, E.C. Kumbur, J. Power Sources 247 (2014) 489-496.

[52] M. Boota, K.B. Hatzell, M. Beidaghi, C.R. Dennison, E.C. Kumbur, Y. Gogotsi, J. Electrochem. Soc. 161 (2014) A1078-A1083. 
Fig. 1. Two-dimensional configurations of RFBs without and with flow fields: (a) classic flow cell without flow field (not drawn to scale) and (b) flow cell with flow field (not drawn to scale)

Fig. 2. (a) Two-dimensional model of flowing through the straight flow channel and over the porous electrode in the RFBs with flow field (not drawn to scale); (b) three-dimensional model (not drawn to scale): (b.1) straight flow channel over porous electrode, (b.2) serpentine flow channel over porous electrode and (b.3) landing/rib view of (b.2) and (c) an example of refined mesh for a part of the flow channel and porous electrode domains of (a)

Fig. 3. Schematic diagram of possible electrolyte flow types in RFBs with serpentine flow field:

(a) incoming electrolyte flow is perpendicular to serpentine flow field without head flow channel;

(b) incoming electrolyte flow is perpendicular to serpentine flow field with a head flow channel;

(c) incoming electrolyte flow is parallel to serpentine flow field; (d) two-dimensional flow channel-porous electrode view of (a); (e) two-dimensional flow channel-porous electrode view of (b) and (f) two dimensional flow channel-porous electrode view of (c)

Fig. 4. Non-dimensional flow patterns for $u_{f}{ }^{*}\left(u_{f} u_{i n}{ }^{-1}\right)$ and $\left\langle u_{p}\right\rangle^{*}\left(\left\langle u_{p}\right\rangle u_{i n}{ }^{-1}\right)$ with $Y^{*}\left(Y\left(t_{f}+t_{p}\right)^{-1}\right)$ from ideal parabolic flow inlet to developing and fully developed regions in the flow channel and porous electrode at $X^{*}\left(X L^{-1}\right): 0,0.1,0.2$ and $0.7\left(k=9.7 \times 10^{-9} \mathrm{~m}^{2}, \varepsilon=0.78, R e=91.5\right)$

Fig. 5. The trend of normalized $u_{f}{ }^{*}\left(u_{f} u_{i n}{ }^{-1}\right)$ and $\left\langle u_{p}\right\rangle^{*}\left(\left\langle u_{p}\right\rangle u_{i n}{ }^{-1}\right)$ with $X^{*}\left(X L^{-1}\right)$ from 0 to 1 at $\operatorname{six} Y^{*}\left(Y\left(t_{f}+t_{p}\right)^{-1}\right): 0.390,0.319,0.284,-0.071,-0.142$ and -0.213 in the flow channel and porous electrode under ideal parabolic flow inlet condition ("no shoot") 
Fig.6. Dimensionless $P_{f}{ }^{*}\left(P_{f}\left(\rho u_{i n}{ }^{2}\right)^{-1}\right)$ and $\left\langle P_{p}\right\rangle^{*}\left(\left\langle P_{p}>\left(\rho u_{i n}{ }^{2}\right)^{-1}\right)\right.$ distributions along $X^{*}\left(X L^{-1}\right)$ at seven $Y^{*}\left(Y\left(t_{f}+t_{p}\right)^{-1}\right)$ : $-0.213,-0.142,-0.071,0.142,0.284,0.426$ and 0.567 ; (b) and (c) are the corresponding enlarged local curves of (a)

Fig. 7. $v$ velocity distributions at the interface between the flow channel and porous electrode: (a) ideal plug flow inlet condition and (b) ideal parabolic flow inlet condition (single layer of $10 \mathrm{AA}$ carbon fiber paper, $Q_{i n}=20 \mathrm{~cm}^{3} \min ^{-1}$ ) 